\title{
Mineração
}

\section{Análise estrutural no planejamento de lavra de rocha ornamental}

\author{
Daniele Di Giorgio \\ MSc., Univ. Federal do Rio Grande do Sul - Escola de Engenharia - Depart. de Eng. de Minas \\ Av. Osvaldo Aranha, 99-504 - CEP 90035-190 - Porto Alegre (RS) \\ E-mail:dandig@libero.it \\ Jair Carlos Koppe \\ Prof. Dr., Univ. Federal do Rio Grande do Sul - Escola de Engenharia - Depart. de Eng. de Minas \\ Av. Osvaldo Aranha, 99-504 - CEP 90035-190 - Porto Alegre (RS)
}

Telmo Quadros Dr., Fundação Estadual Proteção Ambiental - Rua Carlos Chagas, 55 - CEP 90030-020 - Porto Alegre (RS)

Sergio Klein

MSc., Univ. Federal do Rio Grande do Sul - Escola de Engenharia - Depart. de Eng. de Minas Av. Osvaldo Aranha, 99-504 - CEP 90035-190 - Porto Alegre (RS)

João Felipe Costa Leite

Prof. Dr., Univ. Federal do Rio Grande do Sul - Escola de Engenharia - Depart. de Eng. de Minas Av. Osvaldo Aranha, 99-504 - CEP 90035-190 - Porto Alegre (RS)

\section{Resumo}

A análise estrutural de um maciço rochoso é uma importante ferramenta a ser aplicada ao planejamento de lavra de rocha ornamental. Além do mapeamento das descontinuidades, é importante definir-se como estão distribuídas as tensões no maciço rochoso. Nesse trabalho, apresenta-se uma análise estrutural do Sienito Piquiri, RS, com aplicação no planejamento da lavra. Os dados coletados durante o levantamento estrutural constituíram um banco de dados utilizado para determinar os eixos de paleotensão. A análise efetuada distinguiu duas fases de deformação, sendo possível separar os tipos de fraturas (R, C, T e P). As fraturas com direções entre $260^{\circ}$ e $10^{\circ}$ foram consideradas mais problemáticas em relação às operações de lavra. A identificação das zonas menos intensamente fraturadas permitiu um aumento na recuperação dos blocos de sienito.

Palavras-chave: rochas ornamentais, análise estrutural, planejamento de lavra.

\section{Abstract}

Structural analysis of rock mass is an important tool to be used for mine planning of dimensional stones. Besides the structural mapping, it is important to define the stress distribution within the rock mass. This paper describes the results obtained from the application of structural analysis at the Piquiri Syenite, Rio Grande do Sul, Brazil, to aid dimensional stones quarry planning. Collected data during the structural survey constitute a data base used to determine the paleostress axes. The analyses performed distinguished two phases of deformation and were possible to separate the types of fracture into $R, C$, T e P. Fractures with directions ranging in $260^{\circ}$ and $10^{\circ}$ were considered to impose more difficulties to the operations and planning. Avoiding mining at identified intense fractured zones mass allowed the increase of mining recovery of dimensional syenite blocks.

Keywords: dimensional stones, structural analysis, mine planning. 


\section{Introdução}

A qualidade dos blocos de rocha ornamental obtidos no desenvolvimento das operações de lavra depende, entre outros aspectos, das superfícies de fraqueza da rocha, representadas pelas descontinuidades, e da distribuição de tensões no maciço rochoso. $\mathrm{O}$ conhecimento desses aspectos permitirá uma melhor definição do planejamento de lavra apropriado para cada situação.

Esse estudo compreende a análise estrutural de um maciço rochoso, onde está sendo desenvolvida a lavra do Sienito Piquiri, comercialmente conhecido como Marrom Guaíba, localizado nas proximidades do município de Encruzilhada do Sul, Estado do Rio Grande do Sul.

Nessa análise estrutural, objetivouse o seguinte: (i) a determinação dos elipsóides de paleotensões e (ii) as análises geométricas, dinâmicas e cinemáticas das estruturas locais, auxiliando na identificação das estruturas na escala das operações de lavra. O conhecimento das estruturas e da distribuição de tensões permite um melhor planejamento de lavra, oportunizando, também, a extração de blocos mais adequados ao posterior beneficiamento.

\section{Aspectos geológicos}

O Sienito Piquiri representa um stock circular de idade neoproterozóica, cuja superfície aflorante tem forma de ferradura. Está intrudido em paragnaisses e ortognaisses, respectivamente, dos complexos Metamórfico Várzea do Capivarita e Gnáissico Arroio dos Ratos e em xistos do Complexo Metamórfico Porongos, sendo, por sua vez, cortado por apófises de rochas sienograníticas neoproterozóicas da Suíte Granítica Encruzilhada do Sul (Bitencourt et al., 1993).

Dois grandes grupos de estruturas foram constatados pelos estudos anteriores: a) estruturas do tipo dúctil e b) estruturas do tipo frágil (Jost et al., 1985). As estruturas do tipo dúctil, estruturas tipicamente de fluxo magmático, são constituídas principalmente pela lineação magmática, pela laminação magmática e pela presença de enclaves orientados, além de zonas de falha do tipo dúctil (Vieira et al., 1989).
A lineação mineral, resultado da orientação de cristais de feldspato e anfibólio, apresenta caimento moderado, enquanto a laminação mineral formada pelo assentamento de cristais prismáticos de feldspato e anfibólio, segundo suas faces maiores, mostra forte mergulho.

As estruturas do tipo frágil são caracterizadas por descontinuidades (juntas e falhas) distintas, teoricamente, em dois grupos básicos: i) estruturas associadas à consolidação da intrusão e ii) estruturas associadas aos falhamentos regionais (Jost et al., 1985). O primeiro grupo de estruturas abrange fraturas caracterizadas por três diferentes padrões: padrão radial, padrão anelar e estruturas de alívio (Jost et al., 1985). As fraturas anelares são, em geral, concordantes a subconcordantes com a laminação magmática e podem ser o resultado da contração por resfriamento do corpo sienítico.

As fraturas radiais interceptam em vários ângulos as superfícies de fraqueza representadas pela laminação magmática. Essas fraturas foram geradas a partir da consolidação do sienito (Jost et al., 1985). As fraturas de alívio são geradas como resposta à erosão do topo da intrusão, de modo que ocorrem com pequeno mergulho, ou seja, são horizontais a suborizontais. As estruturas que podem estar associadas a falhamentos regionais ocorrem nas seguintes direções preferenciais: NNW, NW, NE e EW (Jost et al., 1985).

\section{Metodologia}

Um dos principais aspectos no mapeamento estrutural compreendeu a adaptação da metodologia usada na coleta de dados de controle geológico estrutural para a escala das frentes de lavra do sienito. Essas atividades tiveram como finalidade a formação de um banco de dados para a geração de modelos plausíveis das descontinuidades e, futuramente, para a elaboração de melhores cenários de planejamento de lavra.

Para o estudo das estruturas, preliminarmente foi executada uma análise baseada em fotografias aéreas da região, na escala 1:25.000. Nessa análise foram extraídos lineamentos do tipo 2 , segundo metodologia e classificação descritas em Amaro e Strieder (1994). Esses lineamentos relacionam-se às estruturas frágeis e foram extraídos com o objetivo de possibilitar o melhor entendimento das estruturas regionais, bem como a geometria e os contatos da intrusão Sienito Piquiri, posteriormente confirmados no campo (Figura 1).

$\mathrm{Na}$ seqüência, foram mapeadas as descontinuidades nos afloramentos e nas frentes de lavra. Com o objetivo de obter-se um melhor entendimento do comportamento das estruturas e de sua classificação, foram coletados 26 dados de "slickensides" e "steps" nos planos de falha, destinados à determinação do elipsóide de paleotensões. Após uma análise inicial, decidiu-se pela separação em dois grupos de dados denominados "A" e "B", pois esses se mostraram incongruentes quando analisados em conjunto.

Os dados separados (grupos A e B) foram, então, processados de acordo com a metodologia dos diedros direitos proposta por Angelier e Mechler (1977). O princípio desse método consiste em procurar as orientações dos eixos que estão somente nas áreas das possíveis orientações dos eixos $\sigma_{1}$ (ou o eixo $\sigma_{3}$, respectivamente) para o conjunto inteiro homogêneo de mecanismo focal analisado. As outras orientações são excluídas. O resultado é a visualização de todas as possíveis orientações teóricas dos eixos principais de tensões $\left(\sigma_{1}\right.$ ou $\left.\sigma_{3}\right)$. Esse procedimento foi necessário para permitir a definição do elipsóide de paleotensões e a conseqüente cinemática das juntas.

\section{Resultados}

No caso do Sienito Piquiri, dois grandes grupos de estruturas foram identificados com base em trabalhos de campo: i) estruturas do tipo dúctil e ii) estruturas do tipo frágil, o que coincide com os estudos efetivados anteriormente por Jost et al. (1985). 
As estruturas do tipo dúctil são tipicamente de fluxo magmático constituídas, principalmente, por lineação magmática, laminação magmática e pela presença de enclaves orientados, além de zonas de falha do tipo dúctil.

A orientação da laminação magmática é variável, tendendo a acompanhar a forma circular do corpo intrusivo. $\mathrm{Na}$ área da lavra, devido ao efeito de escala, a curvatura da laminação não é perceptível, apresentando uma direção azimutal praticamente constante de $107^{\circ}$.

Os resultados gerais obtidos a partir de trabalhos de campo e da análise estrutural podem ser visualizados na Figura 2, onde são mostrados os diagramas sinópticos produzidos a partir das medidas das estruturas observadas nas frentes de lavra e afloramentos vicinais. Foram identificados pelo menos cinco padrões de estruturas: i) estruturas NNW, com mergulhos predominantes para NE; ii) estruturas NW, com mergulhos predominantes, também, para NE; iii) estruturas NE, com mergulhos predominantes na direção SE; iv) estruturas EW, com mergulhos predominantes para sul e v) estruturas horizontais a suborizontais. Os quatro primeiros padrões já haviam sido identificados no trabalho de Jost et al. (1985). As estruturas suborizontais foram mapeadas devido aos cortes de lavra existentes, uma vez que estas não seriam detectáveis nos afloramentos.

Os primeiros três grupos de estruturas podem estar relacionados a padrões estruturais regionais, porém fraturas radiais associadas ao estágio de consolidação da intrusão podem, também, estar superpostas nessas direções. Muitas vezes esses padrões ocorrem com preenchimento de veios de quartzo e/ou material granítico.

O segundo grupo de fraturas são, possivelmente, regionais e podem, também, ter a superposição de estruturas de padrão anelar relacionadas à intrusão e resfriamento do sienito. Em geral, possuem a mesma direção da laminação magmática.

A Figura 2a mostra um diagrama de rosetas, onde podemos identificar a dis- tribuição das estruturas, com exceção, é claro, das suborizontais. A intensidade elevada de fraturas NNW mascara a presença das fraturas NW, que acabaram sendo diferenciadas pelo mergulho. Em termos de quantidade de fraturas subverticais, aparecem três direções principais que englobam a quase totalidade das mesmas, sendo as fraturas com direção em torno de NNW as mais abundantes. A Figura $2 b$ mostra a distribuição dos pólos das fraturas, onde se evidencia a predominância de mergulhos próximos da vertical na maioria das estruturas.

As estruturas horizontais encontram-se muitas vezes preenchidas por água e argilo-minerais. Essas fraturas são tipicamente relacionadas ao alívio de carga ocorrente principalmente nas regiões de cúpula da intrusão. Nas Figuras 3 e 4, observa-se a nítida existência de duas

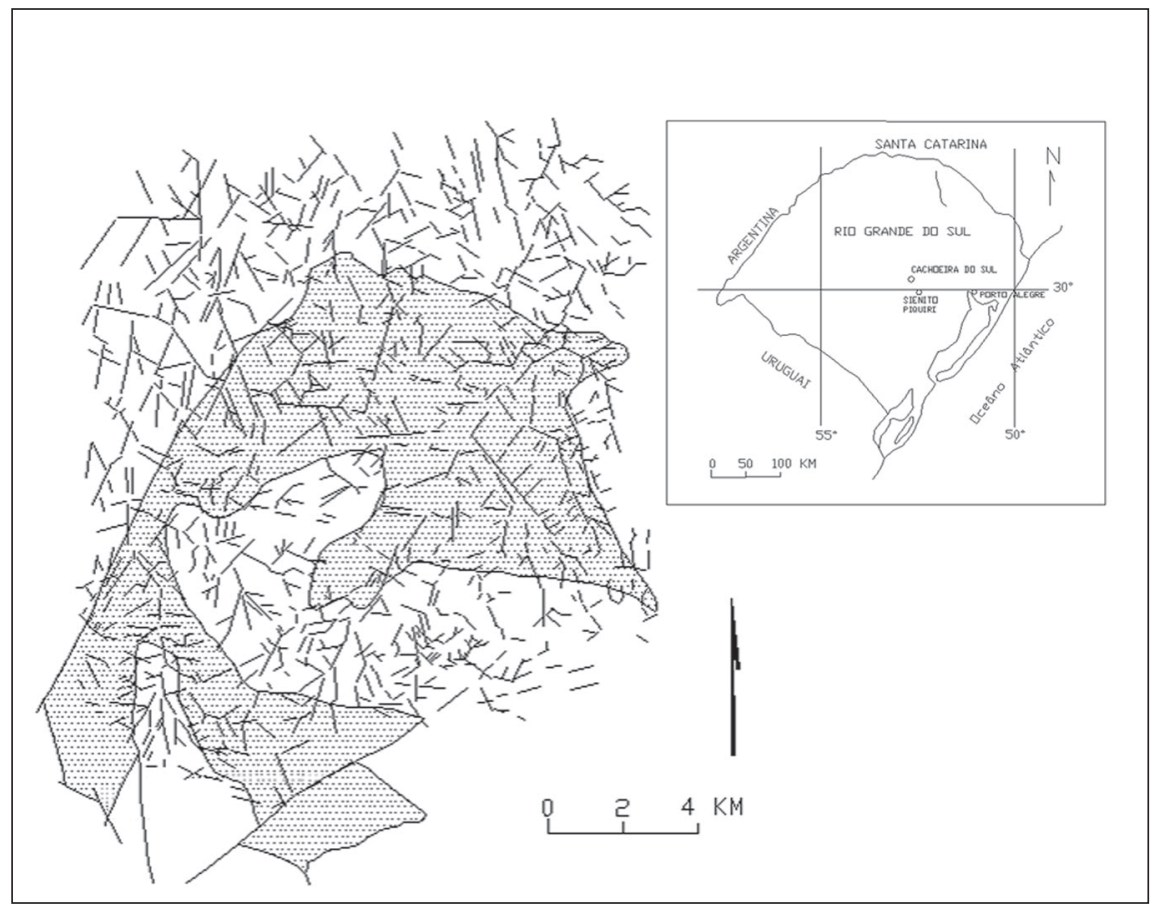

Figura 1 - Localização da área de estudo (topo superior à direita) e mapa das descontinuidades do Sienito Piquiri. A região pontilhada identifica o Sienito Piquiri. O conjunto de pequenos segmentos identificam os lineamentos tipo 2 e os segmentos contínuos maiores correspondem a falhas e contatos do sienito com as outras rochas encaixantes.

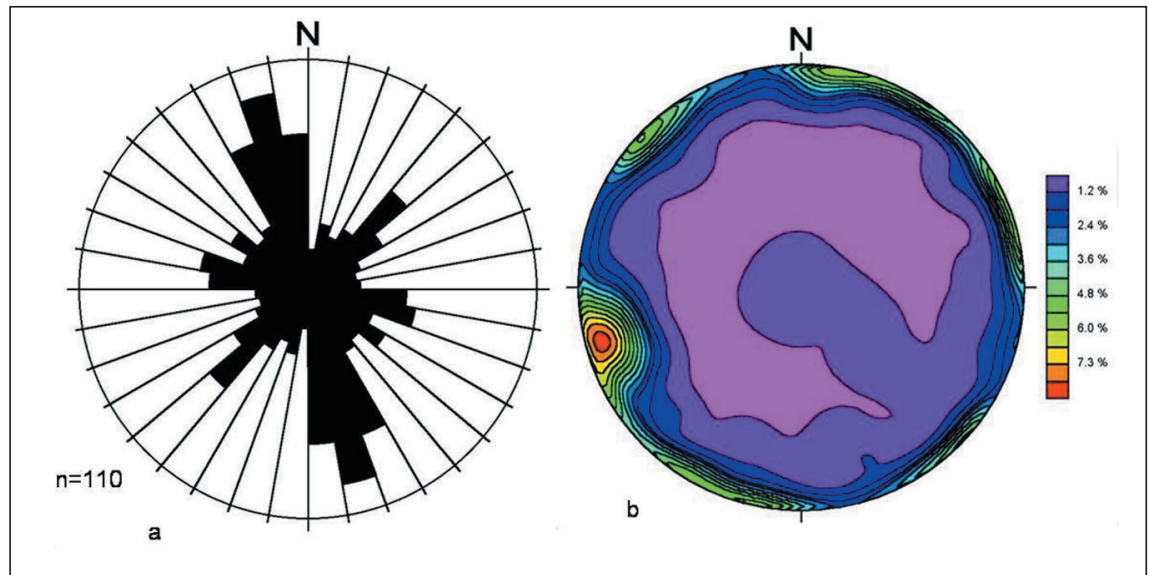

Figura 2 - Diagramas sinópticos produzidos com auxílio do software Stereonet@ a partir de redes de Schmidt. a) Diagrama de roseta mostra as direções das fraturas medidas. b) Diagrama de contorno estrutural mostrando a distribuição dos pólos das fraturas medidas. 
fases de deformação geradoras de estruturas, essas fases foram denominadas "A" e "B", conforme o respectivo grupo de dados associado.

A Fase A apresenta o eixo de tensão $\sigma_{1}$ próximo ao norte e o eixo de tensão $\sigma_{3}$ próximo à oeste, enquanto a Fase B mostra os eixos em posição inversa em relação aos eixos da Fase A.

A análise dos diagramas comprova o caráter essencialmente transcorrente das estruturas encontradas na região, conforme indicado pelo posicionamento aproximadamente horizontal dos eixos $\sigma_{1}$ e $\sigma_{3}$ das duas fases de deformação.

Os padrões mostrados nos diagramas indicam, segundo o método adotado, elipsóides intermediários entre os termos radicais, oblatos e prolatos, sugerindo a predominância de tectonitos LS na área estudada. Os estudos de campo efetuados até o momento não permitem inferir a ordem cronológica da atuação dessas duas fases deformacionais, visto que a fase posterior parece ter reativado algumas zonas de fraqueza geradas durante a primeira fase de deformação. Além disso, essas zonas de fraqueza podem, também, ter sido aproveitadas para o estabelecimento das fraturas relacionadas à intrusão do corpo sienítico.

A partir da definição dos elipsóides de tensões, procedeu-se a identificação das estruturas existentes, segundo a teoria dos falhamentos de Anderson (1942). Assim, a fase de deformação A gerou estruturas de cinco direções azimutais principais:

- Fraturas tipo T: direções entre $0^{0} \mathrm{e}$ $10^{\circ}$.

- Fraturas sintéticas dextrais tipo R: direções entre $340^{\circ}$ e $360^{\circ}$.

- Fraturas sintéticas dextrais tipo C: direções entre $310^{\circ}$ e $330^{\circ}$.

- Fraturas sintéticas dextrais tipo P: direções entre $290^{\circ}$ e $300^{\circ}$.

- Fraturas antitéticas sinistrais tipo P': direções entre $50^{\circ}$ e $70^{\circ}$.

A fase de deformação B gerou quatro estruturas principais:

- Fraturas tipo T: direções entre $260^{\circ} \mathrm{e}$ $270^{\circ}$
- Fraturas sintéticas sinistrais tipo R: direções entre $270^{\circ}$ e $290^{\circ}$;

- Fraturas sintéticas sinistrais tipo C: direções entre $310^{\circ}$ e $330^{\circ}$;

- Fraturas sintéticas sinistrais tipo P: direções entre $340^{\circ}$ e $360^{\circ}$.

Frisa-se que as direções entre $190^{\circ}$ e $200^{\circ}$ e entre $230^{\circ}$ e $240^{\circ}$, que poderiam ser representantes de fraturas antitéticas dextrais P' e R', respectivamente, necessitam de uma análise mais aprofundada em função do reduzido número de fraturas desse tipo encontradas.

\section{Discussão}

O padrão de fraturamento é estritamente ligado à orientação dos esforços que se instauraram no maciço. A partir da determinação do elipsóide de deformação, que caracteriza um dado maciço rochoso, podem ser posicionadas as estruturas deformacionais produzidas pelo campo de tensões diferenciais.

No caso em estudo, as deformações produzidas no maciço sienítico pelas tensões podem ser analisadas por meio de

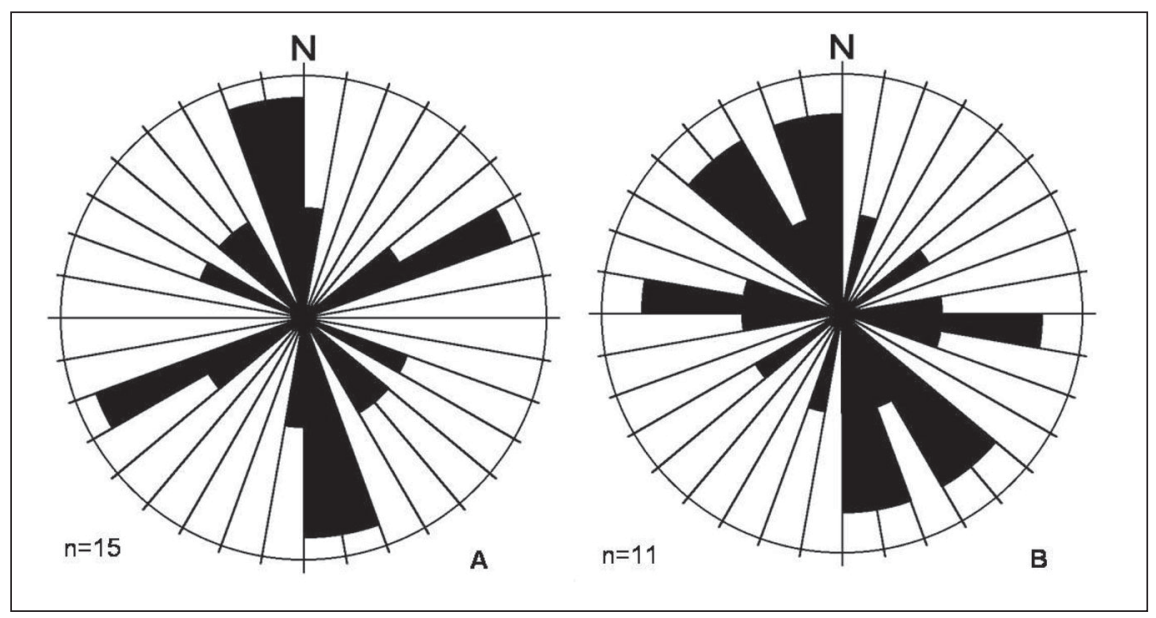

Figura 3 - Diagramas sinópticos produzidos com auxílio do software Stereonet ${ }^{\circ}$ a partir de redes de Schmidt. (A) Diagrama de roseta que mostra as direções das fraturas com estrias medidas na área de lavra relativas à Fase de Deformação A. (B) Diagrama de roseta que mostra as direções das fraturas com estrias medidas na área de lavra relativas à Fase de Deformação $\mathrm{B}$.

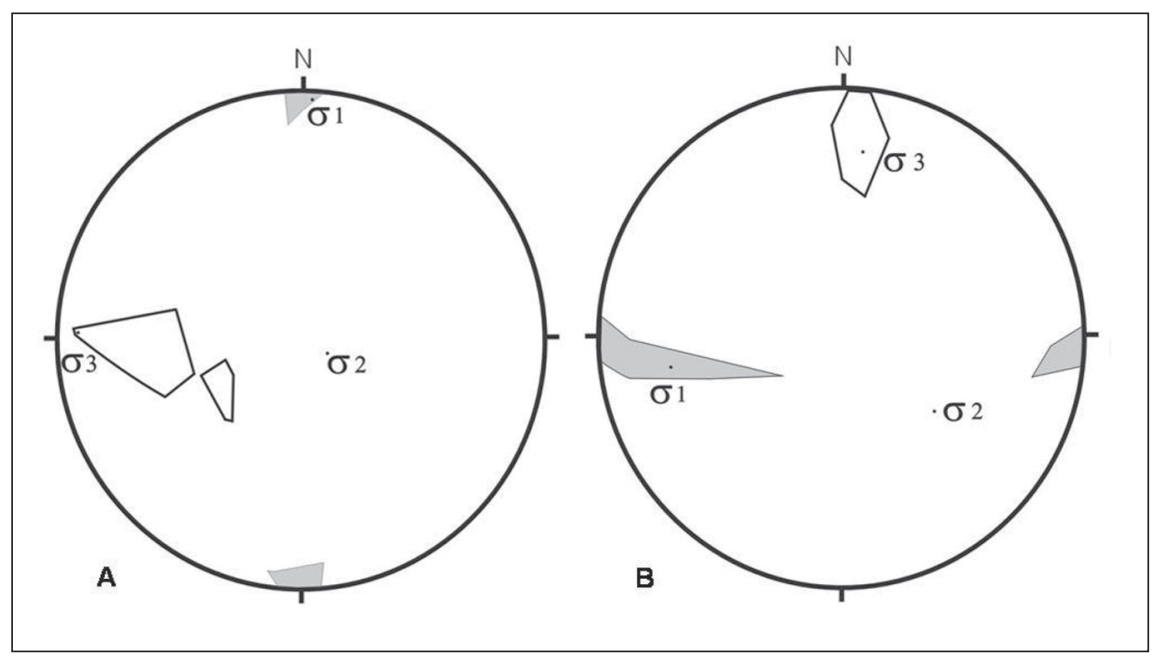

Figura 4 - Diagramas de contorno estrutural (pólos das fraturas), onde se mostra a densidade dos pólos dos mergulhos das fraturas com estrias medidas na área de lavra. O diagrama A mostra os eixos de paleotensões resultantes da aplicação do método dos diedros direitos (Angelier \& Mechler, 1977) referente à Fase de Deformação A. O Diagrama $B$ mostra os eixos de paleotensões resultantes referentes à Fase de Deformação B. 
dois mecanismos específicos de deformação. O primeiro mecanismo gerou as juntas de tração, paralelas aos eixos de máxima deformação. Como exemplos, temos as juntas de resfriamento, juntas trativas (fraturas tipo T), juntas de extensão e juntas de alívio. O segundo mecanismo de deformação gerou as juntas de cisalhamento, as quais formaram pares conjugados, com direções que formam ângulos que variam, aproximadamente, entre $30^{\circ}$ e $60^{\circ}$ com o eixo de máxima tensão $\tilde{A}_{1}$. Essas juntas são relacionadas às falhas regionais.

O estudo da orientação e da movimentação ao longo das estruturas planares demonstra a complexidade estrutural da região. Esse fato pode ser constatado a partir da ocorrência de direções onde houve nítida reativação, pela segunda fase deformacional, de zonas de fraqueza estabelecidas na fase de deformação anterior. Esse parece ser o caso das fraturas de direção entre $340^{\circ}$ e $360^{\circ}$ e $310^{\circ}$ e $330^{\circ}$. Essas fraturas se apresentam com um sentido de movimento em uma fase deformacional e com sentido de deslocamento inverso quando da reativação.

Pode-se aventar a hipótese de que muitas das fraturas com direções azimutais entre $260^{\circ}$ e $010^{\circ}$ tendem a se apresentar abertas, visto que são fraturas sintéticas, independentemente da fase deformacional que as ativou ou reativou. Essas podem ser consideradas mais problemáticas para a lavra, sendo aquelas ao longo das quais pode ocorrer, com mais facilidade, a separação dos blocos, redundando em uma menor recuperação.

A orientação da laminação é um parâmetro que influencia a atividade de lavra no Piquiri. Os blocos devem ser cortados de modo que a orientação das faces principais permita que as chapas a serem produzidas nos teares sejam paralelas à laminação, o que traz os melhores resultados no próprio corte e no polimento das mesmas.

Devido aos cortes preexistentes e a algumas facilidades de acesso, a lavra estava sendo desenvolvida sem utiliza- ção dos dados estruturais, encontrando-se algumas dificuldades para se atingirem as metas de produção e obtendose recuperações muito baixas (Klein et al. 2002).

Considerando-se que a qualidade de um bloco de rocha, extraído no processo de lavra, depende das superfícies de fraqueza da rocha, representadas pelas descontinuidades de qualquer natureza, o conhecimento dos padrões dessas superfícies de fraqueza possibilita estabelecer-se um planejamento de lavra apropriado para cada situação.

A análise geoestrutural efetuada sugere uma orientação e planejamento das frentes de lavra seguindo alguns critérios que possibilitam um maior aproveitamento dos recursos. Além do descarte das zonas com maior intensidade de fraturamento, os cortes executados na rocha, tanto na individualização de blocos, como no seu desdobramento, quando possível, devem ser orientados em concordância com fraturas abertas (trativas). Na locação e orientação de frentes de lavra, devem ser priorizadas as áreas em que as direções das fraturas abertas mais abundantes (NNE e NW) coincidam com a direção da laminação magmática local.

\section{Conclusões}

Em maciços fraturados, a determinação da distribuição das fraturas é fundamental para um planejamento de lavra capaz de maximizar a recuperação de blocos calibrados. A correta visualização tridimensional dos planos de fraturas viabiliza o conhecimento do tamanho e orientação dos vários blocos que podem ser extraídos ou de quais setores podemos recuperar blocos calibrados, mediante o desdobramento em cortes. A análise de paleotensões mostrou ser uma ferramenta importante para a análise e o suporte às decisões relacionadas ao planejamento da lavra de rochas ornamentais, podendo colaborar com o melhor entendimento de situações adversas, como rupturas imprevistas de blocos em determinadas direções, que podem ocorrer durante a lavra.

Deve ser considerado que o levantamento geológico básico e a análise estrutural não são suficientes para superar as dificuldades na determinação da geometria dos blocos comerciais durante o planejamento de lavra. Além de uma análise estrutural consistente, para aumentar sensivelmente as chances de sucesso do planejamento da lavra são necessários: acompanhamento topográfico adequado à escala de trabalho, modelagem tridimensional do maciço rochoso e das estruturas baseada na utilização de técnicas geofísicas e geoestatísticas.

\section{Referências bibliográficas}

ANGELIER, J., MECHLER, P. Sur une méthode graphique de recherché des contraintes principales également utilizable en tectonique et en sismologie: la méthode des diédres droits. Bulletin Societée Géologique, France, v.7, n. 6, p. 13091318, 1977.

AMARO, V. E., STRIEDER, A. J. Análise de fotolineamentos e de padrões estruturais em imagens de satélite. In: CONGR. BRAS. GEOL., 38, 1994. Balneário Camboriú, Santa Catarina, Brasil, Bol. Res. Exp., v. 1, p. 443-444, 1994.

ANDERSON, E. M. The dynamics of faulting. Edinburgh: Oliver and Boyd, 1942. 183 p.

BITENCOURT, M.F. et alii. Reavaliação preliminar das relações estratigráficas do Complexo granítico Encruzilhada (CGE), RS. In: PRIMER SIMPÓSIO INTERNATIONAL DEL NEOPROTEROZOICO-CAMBRICO DE LA CUENCA DEL PLATAN. Uruguay, Resumenes extensos, tomo II, 1993.

JOST H. et alii. Geologia estrutura, petrografia e petrologia do Sienito Piquiri (Proterozóico Superior), Rio Grande do Sul. SBG, In: SIMPÓSIO SUL-BRASILEIRO DE GEOLOGIA, 2, Florianópolis, Anais..., p. 63-81, 1985

KLEIN, S. L., et alii. Técnicas para a otimização do planejamento da lavra de rochas ornamentais. In: CONGRESSO BRASILEIRO DE MINA A CÉU ABERTO, 2, 2002, Belo Horizonte, Minas Gerais, Brasil. Trabalhos técnicos. Ibram, UFMG. 2002

VIEIRA Jr. N. et alii. Enclaves microgranulares do Maciço de Piquiri - RS. Acta Geológica Leopoldensia, v. 29, p. 185-206, 1989.

\section{Artigo recebido em 16/05/2003 e} aprovado em 11/09/2003. 